\title{
Arsenic influence on the distribution and modes of occurrence of gold during the fluid-pyrite interaction: a case study of pyrite from the Qiucun gold deposit, China
}

HE ZHANG ${ }^{1,2}$, YUANFENG CAI ${ }^{1}$, GANG SHA ${ }^{3}$, JOËL BRUGGER ${ }^{4}$, ALLAN PRING ${ }^{2}$, PEI NI ${ }^{1}$, GUJIE QIAN ${ }^{2}$, ZHENJIAO LUO ${ }^{3}$, YANG ZHANG $^{1}$, WEI TAN ${ }^{5}$

${ }^{1}$ Nanjing University, Nanjing 210023, China

(*correspondence: caiyf@nju.edu.cn)

${ }^{2}$ Flinders University, Adelaide 5001, Australia (allan.pring@flinders.edu.au)

${ }^{3}$ Nanjing University of Science and Technology, Nanjing 210094, China (gang.sha@njust.edu.cn)

${ }^{4}$ Monash University, Melbourne 3800, Australia (joel.brugger@monash.edu)

${ }^{5}$ Guangzhou Institute of Geochemistry, Chinese Academy of Sciences, Guangzhou 510640, China (tanwei@gig.ac.cn)

Different modes of gold are common in arsenian pyrite from epithermal gold deposits, but little is known about the effect of arsenic on distribution and modes of occurrence of $\mathrm{Au}$ in pyrite during fluid/rock interactions in epithermal systems. Here we present a detailed study using a novel combination of scanning electron microscopy, electron probe micro-analyser, laser ablation-inductively coupled plasmamass spectrometry, X-ray diffraction, laser Raman spectroscopy, electron backscatter diffraction, transmission electron microscopy, megapixel synchrotron X-ray fluorescence and atom probe tomography to identify distribution and modes of occurrence of $\mathrm{Au}$ in arsenian pyrite, characterize the structure of host pyrite and interpret $\mathrm{Au}$ behaviours during the hydrothermal replacement of pyrite by As-rich ore-forming fluids. Results show that invisible $\mathrm{Au}$ was enriched as homogeneous solid solution in the As-rich domains of pyrite. As-induced lattice defects by substitutions of As for both $\mathrm{Fe}$ and $\mathrm{S}$ provide space for occupation of invisible $\mathrm{Au}$ in pyrite. In contrast, visible $\mathrm{Au}$ was hosted in either grain boundaries or fissures in As-deficient interiors of pyrite. This study shows that extensive hydrothermal alteration at the fluid-pyrite interface promoted $\mathrm{Au}$ ions to take part in the build-up of As-rich products as homogeneous solid solutions with As-assisted incorporation, but Au ions also diffused along grain boundaries and fissures into the interiors of early pyrite where slower hydrothermal replacement would promote $\mathrm{Au}$ ions to preferentially crystallize as a secondary phase. 